\title{
PRECARIOUS VOICES: THE SHARED HOPES AND DREAMS OF THOSE TEACHING AND SUPPORTING LEARNING IN DIGITAL CONTEXTS
}

Peter Bryant, University of Sydney, Australia, Donna Lanclos, Anodyne Anthropology, LLC, United States of America, David White, University of the Arts London, United Kingdom

\begin{abstract}
University staff in learning technology related roles are critical to the capability of the institution to effectively enhance the student experience, deliver an engaged curriculum and achieve significant pedagogical change. However, their perceptions of identity, precarity, status and capability and the locations and roles they are located in within many institutions can challenge that capability. Drawing on data gathered about the hopes and dreams of over two hundred learning technology related staff at three workshops held in the United Kingdom, Australia and Germany, this paper will explore the contradictions and paradoxes that impact on the capability of staff in learning technology related roles to influence and shape pedagogical and technological change.
\end{abstract}

\section{Introduction}

Designing and implementing strategic pedagogical change is a critical and sometimes intractable challenge for higher education institutions. The imperative to deliver the ambitions of these strategic plans is in part driven by policy agendas that enshrine an internationalised and globalised agenda to compete and be measured against collegiate institutions to ensure survival in a higher education marketplace (Hemsley-Brown \& Oplatka, 2006). Many institutions have found or seek to find competitive advantage through designing or replicating pedagogy and curriculum practices and the application and leveraging of educational technologies (and the data they generate) (Marshall, 2011). This has led to weaponization of practices such as learning analytics, online learning, social media learning and co-design in the fight to ensure survival and success of institutions in an increasingly competitive higher education market (Daniel \& Butson, 2014; Nord, Paliszkiewicz, \& Koohang, 2014; Watters, 2017; Yuan \& Powell, 2013).

How institutions are designing and implementing these strategies for change is fuelling debate that centres on the disruption of the economic and social model of traditional universities and heralding the arrival of new, transformative players (e.g., Christensen, 2013; Weller, 2018). Some writers (e.g., Tapscott \& Williams, 2010) argue that technology is the pivotal force in shaping learning for the emerging "customers" of the modern university. Selwyn (2016a) observes (perhaps slightly wryly) that “...all told, the overriding sense is of the 
fundamental re-alignment and reform of university teaching and learning along digital lines" (Selwyn, 2016a; p.1006). There is little universality in that opinion with other writers (e.g., Blin \& Munro, 2008) running from the benign to the sometimes hostile in describing the impacts of technology on learning and teaching despite how integrated technology is into the delivery of education (Selwyn, 2016b)

One consequence of this strategic activity and competitive frisson has been a growing sense of job insecurity and uncertainty experienced by many higher education staff (both academic and professional) (Pucciarelli \& Kaplan, 2016; Ylijoki \& Ursin, 2013). McNaughton and Billot (2016) argue that teaching and related staff are amongst the first people in institutions to experience challenges to their perceptions of academic identity within the constantly shifting and uncertain institutional discourses on pedagogy and technology. The staff in learning technology related roles (which includes learning technologists, data or technology specialists, designers, academics and educational developers) have a diverse range of influence, agency and authority in the institutional strategic discourse and subsequent actions arising from it (Austen, Parkin, Jones-Devitt, Mcdonald, \& Irwin, 2016; Bryant, 2015; Mitchell, Simpson, \& Adachi, 2017). There is also significant variation in how visible or present they are in the integration of technology into wider strategic initiatives and how they understand or share their own sense of identity, either collectively or institutionally in that context (Browne \& Beetham, 2010; Fox \& Sumner, 2014; Walker \& MacNeil, 2015). This places staff in these roles in institutional positions that are rent with contradictions, centred on where they act in supporting and leading technological change in institutions. The can make their job role feel “...often marginalised and sometimes precarious" (Fox \& Sumner, 2014; p.94)

\section{Addressing precarity, marginalisation and being: Future Happens changehacks}

In response to our own experiences in a variety of University roles that were a part of or led pedagogical and technological change, we came together in 2016 to design a series of workshops that afforded participants the opportunity to share their experiences and fears about the role of technology related staff in the development and delivery of institutional pedagogical change. We called the workshop "Future Happens" as a counter to the narrative that the significant impacts and benefits of learning technology were unrealised and simply "potential" in many institutions (e.g. Christensen \& Eyring, 2011; Kirkwood \& Price, 2014; Selwyn, 2016b). This narrative had been used in all our institutions to simultaneously advocate for more learning technology and to resist and rebel against its use. Future Happens set the marker in the sand that at least for the duration of the workshop, there was no need to debate the arrival and influence of technology in education, it had already happened. We felt it critical to address the impacts of the variability of agency, experience and identity by affording participants the opportunity to collectively define and describe the narrative behind their beliefs and ambitions for technology and pedagogy, rehearsing the words in the safe space of engaged peers and stakeholders. 
The Future Happens workshops involved a mix of invited and self-selected learning technologists, University management, stakeholders such as industry bodies and students and academics brought together to determine how they could be empowered and enabled to be the nexus between practice and strategy. The intention of these workshops was to encourage participants to be part of the discourse at their institution by generating, sharing and challenging the key messages, tools and strategies necessary to put the digital in the heart of the conversation with senior University management (such as the Vice-Chancellor).

Future Happens workshops was run across three countries (the United Kingdom, Germany and Australia) over two years and brought together over two hundred participants from approximately 100 institutions and groups to address the wicked problem of how to be a part of the dialogue around pedagogical change (using several different filters such as social media and scalability and sustainability). Each workshop generated individual and collective outputs centred on the participants themselves (the Burnt activity) and their crowdsourced response to the challenge of integrating technology at a strategic level (the Hacks). The analysis of this paper is focusing specifically on the three workshops we called Future Happens 3 ran in 2017. We have chosen to focus in particular on the critical reflections of participants in learning technology related roles that emerged in the Burnt activity. In Burnt, we sought to sharpen the focus on being a part of the pedagogical change process without the baggage of rehearsed excuses, fears, past experiences or overly ambitious aspirations, before moving on to engaging in collectively participating in participating in defining change through the changehack.

\section{Changehack design}

Building on the practices of a hack which seek to spin scenarios and collectively solve and technology problems, a changehack uses similar principles of time limited engagements, specific rules of participation and a casual but slightly pressured environment of crowdsourcing, to bring together people into a learning community to collectively solve educational and organisational problems (Bryant, Lanclos, \& White, 2016). Before we engaged participants in the hacking process, we wanted to expose and explore their frameworks and experiences of how technology and pedagogical change have impacted them in their own personal experiential frame. Each changehack brought together a disparate, unconnected and unfamiliar group of people, with their own institutional tensions, victories and lenses. The conceit of the workshop was predicated on how these people could imagine an institutional world separate but the same as theirs, free from the things that hold back engagement with pedagogical and technological change.

We opened each changehack with "Burnt" - a simple, but powerful activity. We told participants at each Future Happens 3 workshop (the first in Liverpool, United Kingdom at ALT-C, the second at ASCIILITE in Queensland, Australia, and the third at Online Educa in Berlin, Germany) that we wanted to give them a chance to reflect on their own practices and contexts before we began the changehack itself. Whilst individual and organisational experience and memories are critical to designing and implementing effective change, 
enabling authenticity and practice to inform the discourse (Walsh \& Ungson, 1991), they can also be a rationale to resist or repel change (Bryant, Coombs, \& Pazio, 2014). We told participants that before we could plan for scenarios and imagine new ways of working and thinking, we needed to clear the air and vent their assumptions that might get in the way.

We ask participants to write down their "Hopes and Dreams" for the kind of work they did in education and technology. We then asked for "Victories", moments where they really thought they were successful in their work at their institution (or a previous institution). The final category was "Disasters", a moment where everything went terribly wrong. All of these postits went on the wall of the workshop room to be shared with the entire group. We did a brief reflection on these post-it notes before moving on with the workshop. We chose to use value laden words to prompt engagement with these categories (hopes and dreams, victories, fears, dumb things/nightmares). We wanted the words to be sharply evocative, to provide shortcuts to people being able to unpack swiftly their personal experiences, internal reflections and examples of successful and unsuccessful change. The openness of these terms was a deliberate attempt to create broad areas in which whatever was foremost in a participant's mind could be expressed. We also added a time pressure to the activity to tease out immediate and hopefully more viscerally felt responses.

\section{Hopes and Dreams: exposing the paradoxes of learning technology related roles}

As the rest of the workshop progressed, Donna Lanclos (the anthropologist on the team) spent time sorting through each of the larger Burnt categories to find emergent themes, which we then discussed and preliminarily verified with the workshop participants in the final stages of workshop. We transcribed each of the post-it notes into a spreadsheet, with initial analytical codes generated in the room in the UK and remotely in Australia and Germany. Fundamentally, this was an analytical coding exercise, where we were treating each post-it note as a piece of data (for a total of 300 data points). We applied an inductive analysis methodological approach to the data, which allowed the themes to emerge from what was submitted, rather than imposing the categories we thought would be important from the outset. The themes initially identified by Lanclos, were further verified and refined by all of us in an iterative asynchronous process, primarily within the spreadsheets.

For this paper, we have chosen to focus on the Hopes and Dreams responses only. These responses represented an aspirational, personal perspective on the role of the learning technology related staff, one which was essentially positive and forward thinking. They provided an insight into a vision for the future that contributed towards how the participants understood and participated in the strategic direction of the institution. In describing Hopes and Dreams, participants were describing perceptions, ambitions and states that were not currently present in their working lives. These were transitory states, however much driven by uncertainty, experience or faith and the actions required to move between states of change, are critical components of successful organisational change. Hopes and Dreams were 
descriptors of both the context and the end point of transition, which was critical to success the workshops and for this analysis.

The shared themes that emerged from within Hopes and Dreams were:

- Theme 1: Structural Institutional Support,

- Theme 2: Respect and Social Capital for Tech and Instructional Design,

- Theme 3: Integration of Teaching and learning into Technology,

- Theme 4: Confident Staff and Students,

- Theme 5: Digital Thoroughly Embedded across the whole institution and Theme 6: Digital Facilitating Transformation.

These themes emerged as common in all three workshops, and were not impacted by the geographic location or cultural or institutional role of the participants. The unanimity of the responses was not expected in the design of Burnt. We hypothesized that the diversity of voices in the room and the complex and unique policy frameworks impacting on each University sector would generate very different experiences for people in learning technology related roles. Whilst the change occurring at their institution might have been radically different (or strikingly familiar), how those changes made them feel, how they learnt from it, how they located where the pressure or pain points were and how they understood their own reactions and emotions were experientially common. The Hopes and Dreams responses also explored the enablers and barriers within an institutional system, offering insights into how the participants were not entirely in control (and sometime not at all) of their own actions. The institutional environment, the limitations of technology (and potentially technological determinism) and interactions with other players in the process (and their own reactions and responses) emerged. Hopes and Dreams exposed a complex human ecosystem that may not be visible to those determining the types of pedagogical change occurring in institutions.

\section{Theme 1: Structural Institutional Support}

The desire for greater institutional support for the work of technology in education cannot always be reduced to the claim for "adequate (or more) funding" but that was certainly one of the things highly visible within this theme. However, Hopes and Dreams that referenced

"Support" went past the requirement for more money. There was a real and recognised need for the integration of learning technology related professionals and their expertise into the structures and standardised workflows of their respective institutions. People wanted to be a part of "how we do things" not just an optional add-on, or an after-the fact gloss to decisions that had already been made around process and pedagogy. This desire to be part of the structures determining the direction of education and the student experience was a key insight. How staff in learning technology related roles valued what they could bring to the discourse and how their skills and knowledge could make the strategy better was strongly present in the responses, best demonstrated by this response from a UK participant, "Being able to have projects from any part of the university bid for time for it (to) be an active community of support". 


\section{Theme 2: Respect and Social Capital for Technology and Instructional Design}

The desire to be treated as a professional in their own right, with expertise and a clear, defined voice in change that impacts directly on their identity and self-belief was a necessary accompaniment to the need for structural support. Allusions to an academic-professional staff divide emerged within this theme and it feels important to note that if people experienced such professional respect in their everyday lives, it may not be in the "Hopes and Dreams" responses, but in the "Victories" one. One post-it summed this up noting, "Professional staff are recognised as professionals". This theme was closely related to the first theme, but that critical importance of the social capital participants could add to the organisations through their engagement with change was the distinguishing factor, with one participant in the UK hoping for "Learning technology to be taken seriously as a profession within institution". It was also representative of the critical factors that underpin the professional identity of people in learning technology related roles; respect for expertise, the capacity to make things better and the ability to contribute were all key to defining identity.

\section{Theme 3: Integration of Teaching and learning into Technology}

This theme represented the idea that the work of technology and teaching (and learning) could not be separated, but was entwined via the skills and expertise of many professionals working together on curriculum development and delivery in both physical and digital places. It was clear that participants felt separated from the teaching and learning processes and conversations in their institutions, and that their expertise was not being used by their fellow teaching academics (as opposed to senior management or the institution more broadly). One respondent described this as a hope that "Technology (is) used to support quality pedagogy". Another aspect of this theme was the hope that the pejorative positioning of the digital as a second-class or inferior form of teaching and learning would end, as one UK participant noted "Stitch the digital and the physical into the fabric of learning - no more digital divide".

\section{Theme 4: Confident Staff and Students}

The words engaged and comfortable and collaborative were visible in this theme, speaking to a desire for academics and students alike to be willing to try what might be possible with technology in education, and to be provided opportunities to see what happens when they do try (even if it doesn't all go according to plan). Students and academic staff were seen as unwilling (and sometimes unable) to wrangle tech for themselves such that they could get to a point where new modes of teaching and learning might be possible. Confidence in success or achievement was also a factor of institutional support, not just individual initiative, as one European participant noted "More positive attitude to change - only positive attitude is way to survive and tackle challenges".

\section{Theme 5: Digital Thoroughly Embedded across the whole institution}

Closely aligned to theme 3, Digital Thoroughly Embedded took a more holistic and University-wide perspective on the importance of digital to institutional change, as one UK 
participant noted, "Not needing to put the word 'digital' in front of things anymore". The responses in this theme provided evidence that respondents hoped that technology will become an integral part of the way their institution imagines, creates, and delivers educational experiences. There was a realisation in some responses that this would provide a new set of challenges for people whose work is defined by technology, but that it also might provide opportunities for everyone in educational environments to embed their practice at the DNA level of change. This ambition was described by this European participant hoping, "To get every professional category at university actively engaged in digital education, i.e. teachers, researchers, librarians, ICT-pedagogues, staff support, student support. We're all in it together to put student learning in focus."

\section{Theme 6: Digital Facilitating Transformation}

The stated desire in this theme was for technology to do far more than make things efficient, or to replicate or replace old ways of doing things. Participants wanted to see more of what might be possible that hasn't already been imagined, for digital technology to open space for new and previously untried ways, places, and possibilities within education. This desire for transformation was in tension with the current state of their work, which included tasks around maintaining systems that support traditional modes of teaching and learning (lecture capture, assessment, etc.). This desire for the true transformative potential of technology to be realised was described by this European participant, "Showing that technology can make the learning/education better and that it's not the goal to replace everything with technology, because there still is a lot of reluctance among teachers and students".

\section{Conclusions}

Burnt was designed as an icebreaking activity to start the overall changehack process. However, the "open" character brought to the surface themes which we discovered were shared across numerous institutions and may not have been exposed in the participants' dayto-day work. What the Hopes and Dreams responses clearly demonstrated were the institutional and human reactions to pedagogical change. At an institutional level, the responses highlighted that staff in learning technology related roles often frame the institution as a blocker, and themselves as an "outsider" (this can take many forms) rather than understanding the process of practice and culture change as the central task in hand. One of the ways this manifests itself is the feeling of "not being in the room" where critical strategic decisions are made. This can lead to a sense of "them and us" which often emerges as a lack of agency to shape institutional agendas and the sense that one's own work is at the mercy of senior management who do not share the same educational or institutional philosophy as your own. The themes that emerged from the Hopes and Dreams responses suggest that there is in fact more than one "room" and that people who are classed as learning technology related staff are often in it. And still, status, structures, and siloes get in the way of the work to be done. It also exposed a perception of institutional failures to centre people and process rather than systems and products. This paradox was informed by critical issues of professional identity and respect that shaped the motivation of staff in learning technology 
related roles to become involved in change, sometimes revelling in their perceived role as outsider.

At a human level, how that change made them feel, how they learnt from it, how they located where the pressure or pain points were and how they understood their own reactions and emotions were critical underpinnings to the responses. Despite the intention of the Hopes and Dreams activity to draw the participants into the future through aspiration and grounded fantasy, the frame of current experiences, frustrations and disappointments was front of mind for many participants. Experience and memory are powerful human traits. They are also critical in the process of designing and implementing pedagogical change, bringing to the discourse a sense of authenticity and practice. However, they are also often a rationale or an excuse to resist or repel change. They become rehearsed lines, inculcated in the culture of protecting the ways we do things. In essence, staff become jaded, inured to what appear to be intractable structural and institutional-cultural situations. Within the themes, that sense of defence came through in calls for funding, the declarations of much needed respect and the implicit referencing of those unnamed and unspoken of people who did not want the digital embedded in their institution. There was a further implicit inference in the framing of the responses that suggested a techno-solutionist approach was being taken by "senior management" which squeezed out their teaching and learning expertise in favour of the more utilitarian "keep the technology running" mantra. This may have been driven by pressures on senior management to be expansionist and metrics-driven, while learning technologists and more practice-based staff focus on pedagogy and the quality or character of teaching and learning. The further analysis of the other two Burnt activities could provide some verification of these assertions as in the main they were the unspoken antithesis to the stated hopes and dreams.

Returning to the paradoxical and precarious role of learning technology related staff, it was demonstrable in the responses that our participants identified significant changes that needed to occur within their institutions. In the main these were not related to the purchase of a new piece of technology and neither were they declarations of techno-superiority that simply wished for people to use the technology better. They were pointers to some of the existential threats challenging their ongoing viability of their roles and more widely the notions of teaching and learning itself. Perhaps, the unseen elephant in the room of those who did not share their hopes and dreams may highlight that we as a sector have not fully come to terms with the massification and marketisation of higher education, leading to institutions where the tension between the pressure to expand and survive and holding onto laudable pedagogical approaches has found its nexus in digital technology and the staff employed to inspire others to integrate it into teaching and learning, with the end result being the marginalisation of those critical voices. 


\section{References}

Austen, L., Parkin, H., Jones-Devitt, S., Mcdonald, K., \& Irwin, B. (2016). Digital capability and teaching excellence: an integrative review exploring what infrastructure and strategies are necessary to support effective use of technology enabled learning (TEL).

Blin, F., \& Munro, M. (2008). Why hasn't technology disrupted academics' teaching practices Understanding resistance to change through the lens of activity theory. Computers \& Education, 50(2), 475-490.

Browne, T., \& Beetham, H. (2010). The positioning of educational technologists in enhancing the student experience. Report funded by The Higher Education Academy under its Call4: Enhancing Learning and Teaching through the use of Technology. An ALT Occasional Publication. Retrieved from http://repository.alt.ac.uk/831/1/Tom_Browne_Helen_Beetham_HEA_finalweb.pdf

Bryant, P. (2015). From the middle out: Flipping the role of learning technology from supporting practice to leading change. Paper presented at the apt2015.

Bryant, P., Coombs, A., \& Pazio, M. (2014). Are we having fun yet? Institutional resistance and the introduction of play and experimentation into learning innovation through social media. Journal of Interactive Media in Education, 2014(2), a4.

Bryant, P., Lanclos, D., \& White, D. (2016). What is Future Happens?

Christensen, C. (2013). The innovator's dilemma: when new technologies cause great firms to fail. Harvard Business Review Press.

Christensen, C., \& Eyring, H. J. (2011). The innovative university: Changing the DNA of higher education from the inside out. John Wiley \& Sons.

Daniel, B., \& Butson, R. (2014). Foundations of big data and analytics in higher education. Paper presented at the International conference on analytics driven solutions: ICAS2014.

Fox, O., \& Sumner, N. (2014). Analyzing the roles, activities, and skills of learning technologists: A case study from City University London. American Journal of Distance Education, 28(2), 92-102.

Hemsley-Brown, J., \& Oplatka, I. (2006). Universities in a competitive global marketplace: A systematic review of the literature on higher education marketing. International Journal of public sector management, 19(4), 316-338.

Kirkwood, A., \& Price, L. (2014). Technology-enhanced learning and teaching in higher education: what is 'enhanced' and how do we know? A critical literature review. Learning, Media and Technology, 39(1), 6-36.

Marshall, S. (2011). Change, Technology and Higher Education: Are Universities Capable of Organisational Change? Journal of Asynchronous Learning Networks, 15(4), 22-34. 
McNaughton, S. M., \& Billot, J. (2016). Negotiating academic teacher identity shifts during higher education contextual change. Teaching in Higher Education, 21(6), 644-658.

Mitchell, K., Simpson, C., \& Adachi, C. (2017). What's in a name: The ambiguity and complexity of technology enhanced learning roles. ASCILITE 2017. Retrieved from http://2017conference.ascilite.org/program/whats-in-a-name-the-ambiguity-andcomplexity-of-technology-enhanced-learning-roles/

Nord, J. H., Paliszkiewicz, J., \& Koohang, A. (2014). Using social technologies for competitive advantage: impact on organizations and higher education. Journal of computer information systems, 55(1), 92-104.

Pucciarelli, F., \& Kaplan, A. (2016). Competition and strategy in higher education: Managing complexity and uncertainty. Business Horizons, 59(3), 311-320.

Selwyn, N. (2016a). Digital downsides: exploring university students' negative engagements with digital technology. Teaching in Higher Education, 21(8), 1006-1021.

Selwyn, N. (2016b). Is technology good for education? John Wiley \& Sons.

Tapscott, D., \& Williams, A. D. (2010). Innovating the 21st-Century University: It's time! Educause review, 11.

Walker, D., \& MacNeil, S. (2015). Learning Technologist as Digital Peadgogue. In D. Hopkins (Ed.), The Really Useful \#edtech Book (pp. 91-106). David Hopkins.

Walsh, J. P., \& Ungson, G. R. (1991). Organizational memory. Academy of management review, 16(1), 57-91.

Watters, A. (2017). The Weaponization of Education Data. Hackeducation.com.

Weller, M. (2018). The Digital Scholar Revisited. The Digital Scholar: Philosopher's Lab, 1(2), 52-71.

Ylijoki, O.-H., \& Ursin, J. (2013). The construction of academic identity in the changes of Finnish higher education. Studies in Higher Education, 38(8), 1135-1149.

Yuan, L., \& Powell, S. (2013). MOOCs and open education: Implications for higher education White Paper. 